\title{
Possibilities of Porosity Repairs after Aluminium Alloys Welding
}

\author{
Marian Sigmund (ORCID: 0000-0002-6330-8788) \\ Faculty of Mechanical Engineering, Institute of Manufacturing Technology, Department of Welding Technology \\ and Surface Treatment, Technická 2896/2, 616 69, Brno, Czech Republic, E-mail: sigmund@fme.vutbr.cz
}

This article describes problems of porosity which are caused after welding of aluminium alloys. The main part of this article is dedicated of methods of correction of porosities. The best correction is by welding or by cementation. Described parts are used for welded aluminous vehicle parts in a cooperative company. Thanks to porosity are effected not only ductility and strength of welded structures but also weld quality thereby fall also resulting in surface treatment. Cooperative company is ranked among the world's leaders in development and production automatic, electro-pneumatic and electrically operated door systems for rail vehicles and traffic island as ramps, plateaux 'sand stairs. Staffs of this company have years' experience in the area of welding rail vehicle parts from aluminous alloys. A company has a certificate on welding rail vehicles and their components according to standards EN ISO 15085-2. For public transport company produce sliding doors, driving and inner and among - wagon doors. The same types of doors offer for long-distance transportation and also for high-speed trains. Further, they produce traffic islands, for example, extensible ramp, extensible plateaux, foldaway climbs and bridging, everything is produced from aluminous alloys.

Keywords: Aluminium alloys, Welding, Cementing, Porosity, Public transport.

\section{Introduction}

The problem with porosity on welds is largely on the ground of resulting surface treatment. Surface treatment proceeds so, that the whole part (including welds) is dashed powdery paint. After its whole part is placed to the oven and hot on the melting temperature of powdery paint. Powdery paint will melt and consequently hardened. Arise a continuous layer resistant to oxidation. In case parts with porosity on the surface could come two variants. The first variant is that pores are overlaid by layers of powdery paint. Powdery paint will melt and in pore arise bubble of air that during next warming expands as far as bubble cracks. The integrity of surface treatment is disrupted and a part not pass by visual testing. The second variant is that the powdered paint will seat out at the pore bottom and after powdery paint dab and meltdown will arise in pore cavern that is also for visual testing unacceptable. Example of porosity on the aluminium part of the train door system is shown in Figure 1.

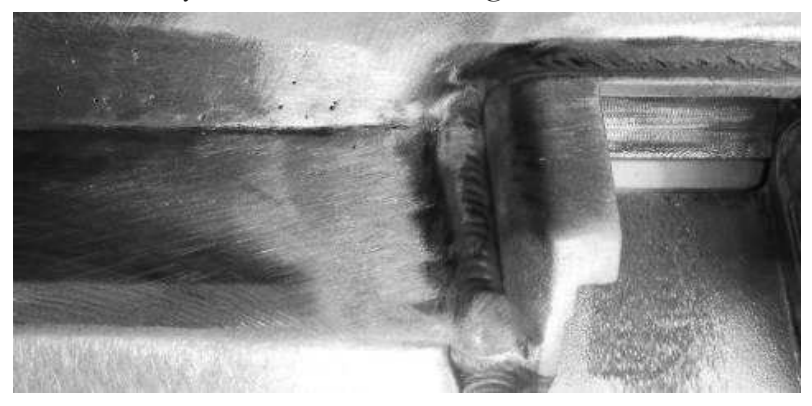

Fig. 1 Porosity example on part train door system
In the cooperative company is production controlled according to standards EN ISO 10042. For welding aluminium and aluminium alloys by arc welding technology are for quality grade $\mathrm{C}$ acceptable any cracks or lines of pores. Average pore acceptable near sheet thickness to the $3 \mathrm{~mm}$ is lower than 0.2 multiple of a rated thickness of butt weld. Near sheet thickness above $3 \mathrm{~mm}$ is acceptable average less than 0.3 multiple rated thicknesses of a butt weld. These pores must be repaired because they will not pass by visual testing according to standards EN ISO 17637. The normal repair process of porosity is put up defects by GTAW (acc. standard EN ISO 4063 by 141) welding method. Unfortunately, repairs by GTAW is time-consuming. Cause average repair of one pore by GTAW welding is about 4 minutes. The experiment described in this article will deal with an alternative method of porosity repair. Namely deals about cementation. Cementation largely could save the time of each repair of one train door system [3].

\section{Experimental Part}

The welded experimental part is the aluminium casting of the door corner. On the corner part of the door case will be solved porosity. In this part, the pores will be often checked after welding. This part is cast from aluminium alloy EN AC-AlSi7Mg0.3 (acc. standard EN 1706). This material is ranked to hypoeutectic silumin and is proper for castings used in the flying or traffic industry. Acts about alloy with high strength and good resistance to oxidation with very 
good casting features. Material grant also demands minimum strength $140 \mathrm{MPa}$, yield strength minimally 80
$\mathrm{MPa}$ and ductility at least $2 \%$. The chemical composition of this aluminous alloy is in Table 1.

Tab. 1 Chemical composition of aluminium alloy EN AC-AlSi7Mg0.3(acc. EN 1706).

\begin{tabular}{|l|l|l|l|l|l|l|l|l|l|}
\hline $\mathrm{Si}$ & $\mathrm{Fe}$ & $\mathrm{Cu}$ & $\mathbf{M n}$ & $\mathbf{M g}$ & $\mathbf{C r}$ & $\mathbf{N i}$ & $\mathbf{Z n}$ & $\mathrm{Ti}$ & $\mathrm{Al}$ \\
\hline 6.59 & 0.107 & 0.012 & 0.023 & 0.434 & 0.0019 & 0.0004 & 0.0093 & 0.135 & 92.7 \\
\hline
\end{tabular}

On drawing Figure 2 are shown the main dimensions of the door corner. This part is welded to the next parts and arise the whole door frame (Figure 3). After welding is weld joints ground, to remove passes between parts acc. Figure 4. Pores in the welding area could extract also after weld regrinding, therefore it is necessary visual inspection.

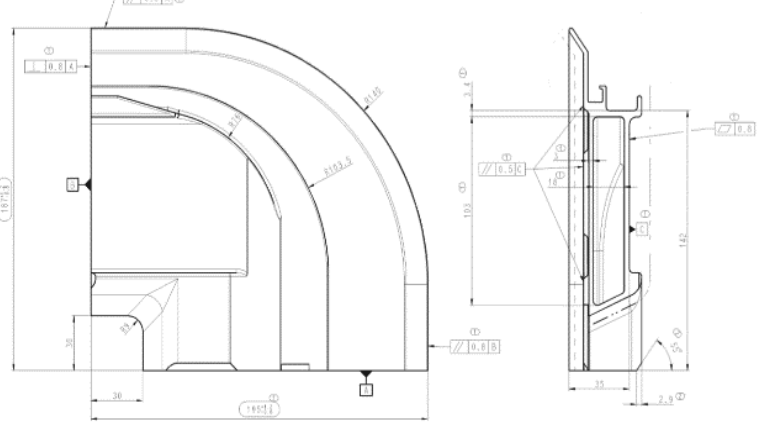

Fig. 2 Door corner drawing with dimensions

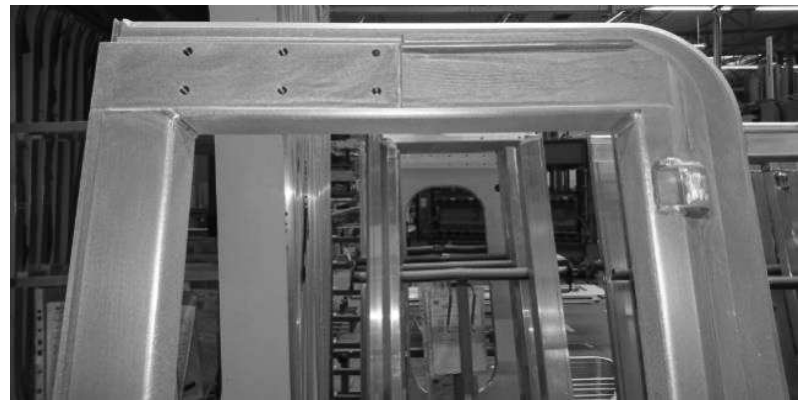

Fig. 3 Whole welded door frame

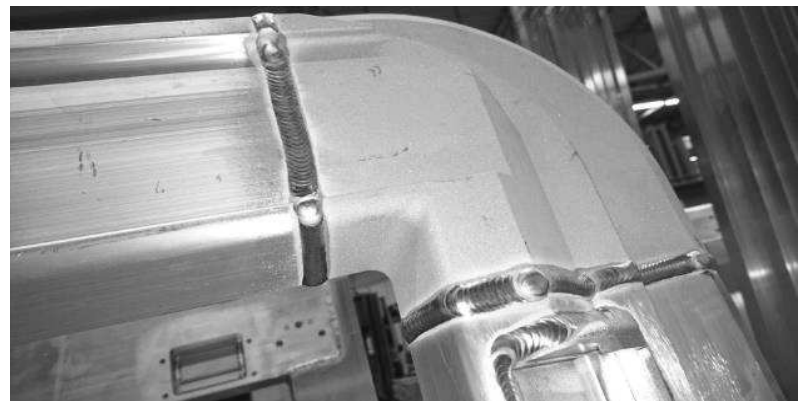

Fig. 4 Door corner detail after welding and grinding

\section{Experiment}

For pores repairs on parts from aluminous alloys is optimal use welding process GTAW as mentioned above, because it is welding no melting electrode in a protective atmosphere of inert gas. The advantage of those welding processes is that not rise a cold joint.
Huge gas solubility in aluminium alloys perform problems with a porosity of aluminium seams. It is then necessary carefully clean and removes the grease from the weld surface and after it avoids contamination with any moisture, fat, and dust. The biggest influence on pores formation has hydrogen, whose bearer is moisture. Sources shall be not only weld surfaces but also filler material that be a necessary good warehouse and eventually dry before using. Further be necessary to remove aluminium oxide, because is high hygroscopic. It means, that the oxide layer absorbs and excludes atmospheric moisture. The unfavourable influence of hydrogen consists of changing his solubility in aluminium depending on temperature (Figure 5). During solidification aluminous weld metal hardly declines solubility hydrogen in aluminium that the quickly granulates. Part hydrogen will stay in the weld metal and their exclusion will get as far as below temperature solidus line. This is results in the formation of pores and bubbles. During the welding process is then good to shorten the straight time of melting and overheating weld metal. With arc welding methods it is possible to use regime with pulsation. Welder first flashes arc and after forming a weld pool, in which pore becomes extinct, welder begins to add filler material. Regarding possibilities regulation frequency and pulsing of range alternate current supported by synergistic power source, especially for welding aluminium alloys, gives considerably limit the quantity of porosity in welds [8].

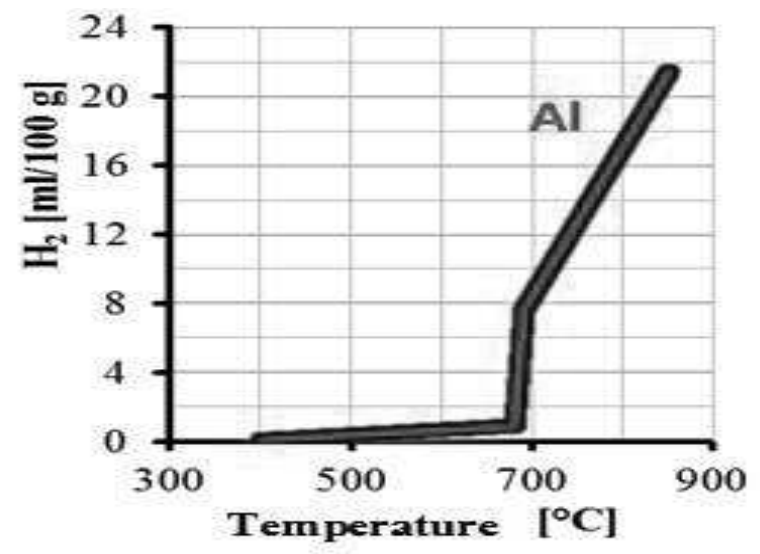

Fig. 5 Influence of bydrogen solubility depending on temperature [8]

Other options for how to limit the number of pores in the weld is used inert gas helium, eventually mixtures helium with argon. Also, another opinion 
shall be correct porosity by cementation. This technology is rather exploited in building industries than in the engineering industry. Since weld repairs are quite common was the aim of this experiment verifies possibility pores repairs by cementation. Therefore, the experiment

was chosen epoxy two-component cement, which is proper for metal cementation, especially for aluminium alloys cementation. Cement should fill up pores cavern with minimum shrinkage. After hardening should cement join with the base material, with a view to the painted surface weren't visible any irregularity.

\subsection{The porosity repairs by welding}

Welding procedure specification for pores repair, more likely GTAW welding parameters is displayed in Table 2.

Tab. 2 Welding parameters for porosity repairs

\begin{tabular}{|ll|}
\hline Welding parameters & Value \\
\hline Filler Material Diameter & $2.4[\mathrm{~mm}]$ \\
\hline Welding Current: Base & $190 \mathrm{~A}$ \\
Impulse & $170 \mathrm{~A}$ \\
\hline Welding speed & $25[\mathrm{~cm} / \mathrm{min}]$ \\
\hline Heat Input & $3.76[\mathrm{~kJ} / \mathrm{cm}]$ \\
\hline Filler Material Type & $\mathrm{S} \mathrm{Al} \mathrm{4043} \mathrm{A}$ \\
\hline Protective Gas & $\mathrm{I} 3-\mathrm{ArHe}-30$ \\
\hline Protective Gas Flow & $15[\mathrm{l} / \mathrm{min}]$ \\
\hline Pre Blowing Time & $1[\mathrm{~s}]$ \\
\hline After Blowing Time & $3[\mathrm{~s}]$ \\
\hline Wolfram Electrode Type & WCe 20 \\
\hline
\end{tabular}

For comparison quantity of pores repairs on the specific underground door frame was chosen two door sets named X and Y. Every set consists of 97 door pieces. I. e. from several door pieces needed for one underground unit. In series $\mathrm{X}$ were pores identified on 30 pieces. Globally was detected 92 pores. Repairs welding time of all pores series $\mathrm{X}$ took 390 minutes. Repair one pore those series $\mathrm{X}$ then took 4.24 minutes. In series, $\mathrm{Y}$ was identified more pores in specific 119. It means, that the be at fault 32 door frames. Repairs welding time whole series Y took 443 minutes and average repairs time of one pore took 3.72 minutes. It is perceptible, that some repairs took more time than others. Welding time of each repair depends on the location of each pore and pores sizes and also on welder skill. From this study is perceptible, that the approximately on every third frame was porosity defect. Acts rather about independent pores than their colony. Several pores on the single door no overreached in one's serial number of nine pieces. Repair time of one's door frame no overreached 40 minutes. Most often repair time proceeds among 10 as far as 15 minutes. General repair time of all pores was for series X 6.5 hours and series Y 7.4 hours. These times are not insignificant. Therefore, look for other variant porosity repairs proper for aluminium door systems, that would be so elaborate and time-consuming. As proper options look repairs by the help of cement. Cementing should reduce repair times and also final costs.

\subsection{The porosity repairs by cementing}

First will be necessary to choose the proper type of cement that has after hardening minimum change of displacement and there is no chance of shrinkage. This cement must have also good surface wettability and grip. A cement must fill the pore and couldn't rise here space for bubbles formation. As an optimal type of cement was chosen epoxy cement with commercial title LOCTITE EA 3479. Acts about double component glue, that is filled by aluminium powder. It consists of gum and hardener, that are mixed in a specific rate 1:1. This cement gets past for repairs or restoration scratched aluminium parts, weldments, casts or piping's. This cement can be also used to filling and buffering surfaces or to repair piping sealing. The main usage finds largely in industrial servicing. The workability time of this cement at room temperature $20^{\circ} \mathrm{C}$ is 45 minutes. Physical and adhesive features for hardened material are mentioned in Table 3. Values are for material, that was hardened for seven days at temperature $22^{\circ} \mathrm{C}$. Cement obtain operational strength at temperature $20^{\circ} \mathrm{C}$ behind 12 hours. In case of lower temperature $10^{\circ} \mathrm{C}$ is time prolongation to 24 hours. Each part after hardening and painting has to pass visual testing [9].

Tab. 3 Characteristics of cement Loctite EA 3479 [9]

\begin{tabular}{|ll|}
\hline $\begin{array}{l}\text { Characteristics Hardened Material } \\
\text { Hardness Tester D }\end{array}$ & Values \\
\hline Linear Shrinkage [\%] & 85 \\
\hline Tensile Strength [N.mm-2] & 0.2 \\
\hline Tensile Strength Modulus [N.mm & \\
Compression Strength [N.mm-2] & 60 \\
\hline Shear Strength [N.mm $\left.{ }^{-2}\right]$ & 6000 \\
\hline
\end{tabular}

This cement, as most epoxy gum, marks excellent resistance to liquids and solvents. Against water and saline is resistance high. Unfortunately, some surfaces could react by discoloration. Good resistance is also against petrol, oil fuelling, and lubricant. On the other hand, it is cement improper for the environment with methanol, acetone or with methyl ketone. To achieve optimum results be necessary to apply cement on the dry, clean and ungreased surface. By any component cement, it is necessary to properly mix first separately and then together. At sizable parts, the damage is possible to use glass fabric as a backup material. Cement is also possible to use as a modelling paste. Be necessary to add wax or grease as a separator that the bite 
adhesion rises to the unsuitable surface. Figure 6 is displayed sample used in the experiment. In area 1 be created a grid with reached holes about diameter $1.5 \mathrm{~mm}$. These holes have simulated so-called artificial created „pores". Were to be created for better clearness, if cement fused with the material. In the area 2 are drilled pores about diameter $1.5 \mathrm{~mm}$ and depth 1 to $2 \mathrm{~mm}$. Acts about original porosity incurred in consequence of the manufacturing process.

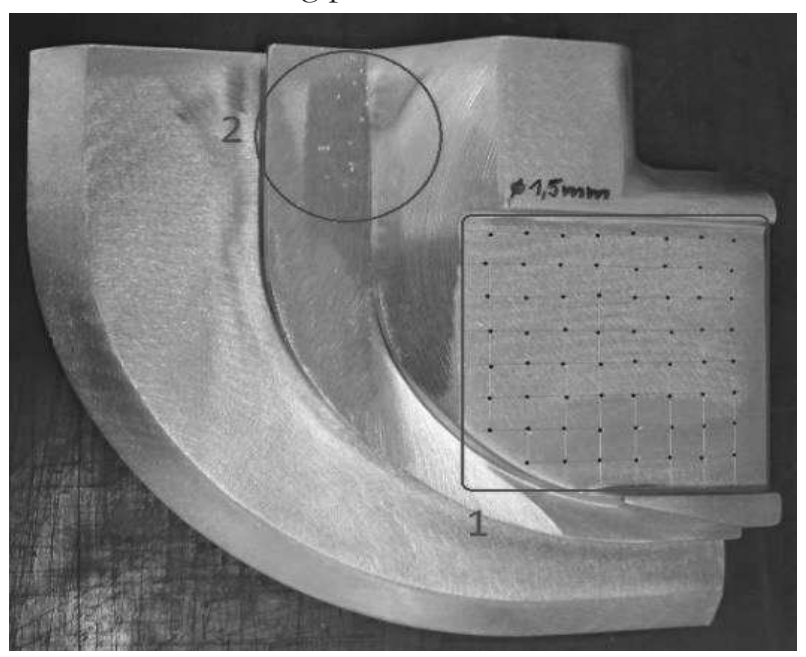

Fig. 6 Sample before cement application

Before cement application was sample roughen by unwoven Scoth fleece. After roughage was surface degrease with the help of cleaner and separator Illbruck AA404. After it was prepared cement. After weight, both components of cement are mixed and it is important, that the mixture was complete. After it is mixture built-up by slice on a part, as is shown in Figure 7. Follows hardening below the pressing machine. The sample was placed to one hour at a temperature of $130^{\circ} \mathrm{C}$ below the pressing machine. After enough long hardening were excess cement layer ground on base material and surface ready for dab powdery paint (Figure 8). After it was sample put in an oven and warm up to powder melting temperature. The thickness of the resulting paint shall be $300 \mu \mathrm{m}$.

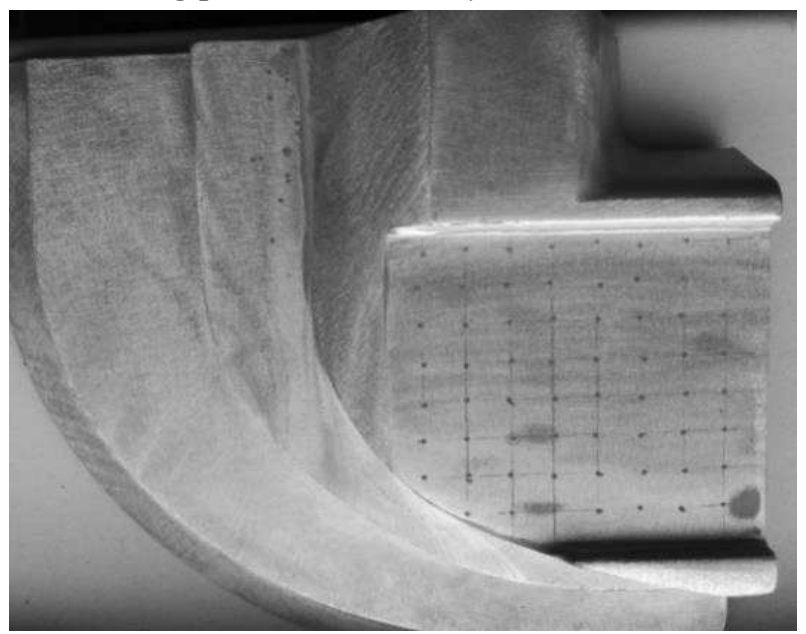

Fig. 7 Sample after cement application

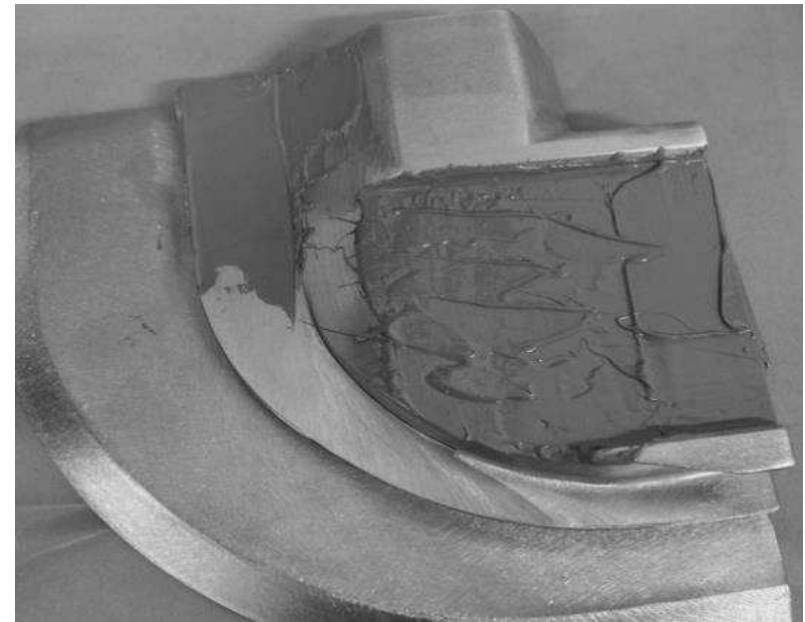

Fig. 8 Sample before powdery paint application

\section{Results and discussions}

Cement has had maintained high temperatures during powdery painting and fulfils requirements for visual testing. The door frame was coated by powder paint and put in the oven. Cement in itself kept up the high temperature, but by visual check, no passed. On frame was visible cementing marks and it is for railway service regulations unacceptable. Cementing marks in the area's original porosity are shown in Figure 9. Figure 10 is shown the surface of artificially created porosity. Here's better seen, that the cement fails to satisfy claim surface line-up and visual testing. Cement besides could create fair-face mistakes and couldn't have standard oxidation resistance.

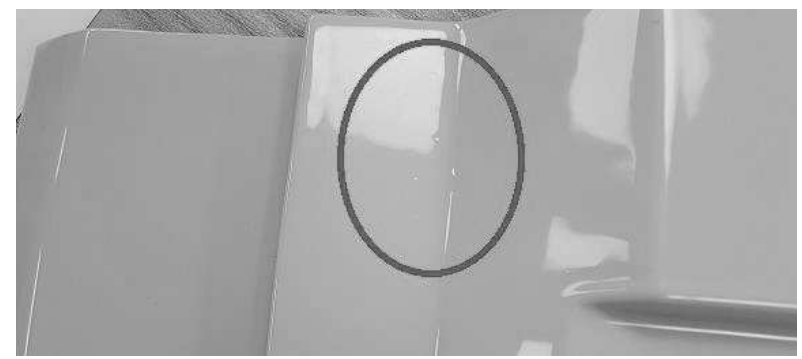

Fig. 9 Sample after application powdery paint in area of original porosity

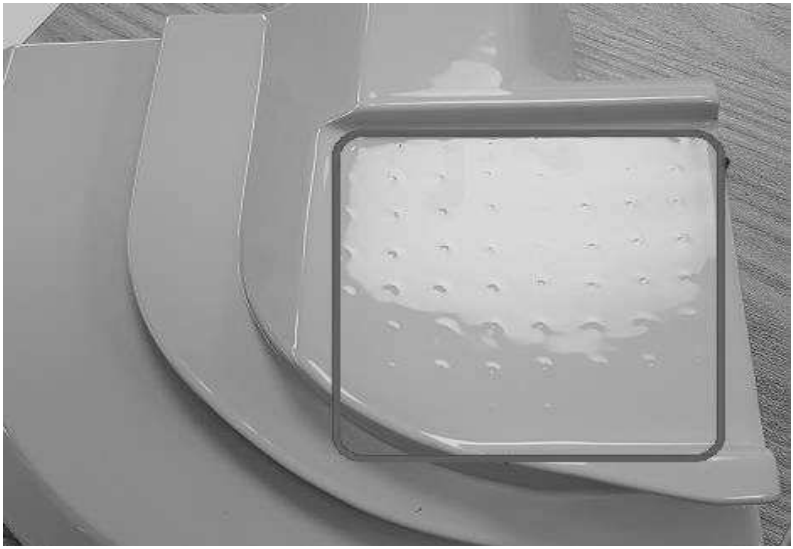

Fig. 10 Sample after application powdery paint in area of artificial porosity 


\section{Conclusions}

For porosity repairs that occur during the technological production process, for example during casting, or porosity that occur during welding is normally used repairs by the GTAW welding method. Porosity in volume is identify on RT films by radiographic testing, but these pores are not repaired. Repaired are only surface pores (pores opened to surface) by visual testing acc. railway standard EN ISO 150852. Visual testing criteria acc. standard EN ISO 5817-C and all repaired pores shall be after welding or cementing repairs acceptable. Thanks, those welding methods are pores welded up. But the GTAW welding method is time - consuming. That was the main reason why we realize an experiment to find an alternative method for porosity repairs on aluminous alloys. As optimal show method of porosity repairs by cementation. As cementing material was specifying epoxy two-component cement. On selected door frame (test coupon) except original porosity artificially were created also grid for better experiment results identification. The surface of the test coupon was roughened and ungreased. After it was on test coupon apply cement layer and also cement must be hardened. Followed brushing of test coupon surface from cement remains. After it was tested coupon coated by powdery paint and was inserted into the oven. Consequently, was a test coupon warm-up on powder melting temperature and thanks that occur continuous paint coat. Quality requirements for test coupons and also the same to the production door frame were visual checks and resulting corrosion tests. According to visual criteria (not acc. standard mean acc. cooperative company internal instruction) must not be visible any marks after cement. This requirement was not passed because cement left markedly caverns. These caverns were not accepted by visual testing. Also, after repair by cementing it is not possible to guarantee the same corrosion resistance as basic aluminium-base alloy. Therefore, was realized internal corrosion tests. These internal corrosion tests confirmed requested corrosive immunity, same as basic aluminous alloys EN ACAlSi7Mg0,3 (acc. standard EN 1706). Therefore, cementing as proper technology for repairs porosity on aluminium alloys was evaluated as available. Unfortunately, this cement used for this experiment was evaluated on surface visual testing as non-acceptable. Will be the next challenge for engineers in cooperative company to find proper cement, that will be proper to use on the surface of door frame produced from aluminium alloys. Until in cooperative company will stay porosity repairs by the GTAW welding method.

\section{Acknowledgement}

Acknowledgments to cooperative company IFE$C R$, a.s., where were realized welding and cementing and VUT FSI Brno, Institute of Manufacturing Technology, Department of Forming, Welding and Surface Treatment, where were realized all evaluated exams and testing.

\section{References}

[1] ŘIHÁČEK, J.; SIGMUND, L. (2018). Production of Rolled Profile and Its Verification by Using Numerical Simulation. MM Science Journal, 2018, roč. 2018, č. 3, s. 2451-2454. ISSN: 1805-0476.

[2] RUDY J.F., RUPERT E.J. (1970). Effect of Porosity on Mechanical Properties of Aluminium Welds. Welding Research Supplement, July 1970, pages 323-336.

[3] ASHTON, F., WESLEY, R.P., DIXON, C.R. (1975). The Effect of Porosity on 5086-H116 Aluminum Alloy Welds, Welding Research Supplement, March 1975, pages 95-98.

[4] MICHNA, Š. et al. (2005). Encyklopedie bliniku, Alcan Děčín, 2005, 700 pages. ISBN 8089041-88-4.

[5] SOBOTKA, J.; SOLFRONK, P. (2018). Influence of Technological Parameters on Ageing of Aluminium Alloy AW-2024, Manufacturing Technology, December 2018, Vol. 18, No.6, page 1023-1028. ISSN 1213-2489.

[6] ŠKEŘÍK, J. (1984). Lepime, tmelime, lakujeme, Albatros, Praha, 1984. ISBN 13-765-84.

[7] OSTEN, M., MLEZIVA, J. (1996). Práce s lepidly a tmely., Grada, Praha, 1996. ISBN 807169-338-3.

[8] FOLDYNA, V. (2001). Materiály a jejich svaritelnost: učebni texty pro kuray sváréčských in ̌̌enyiru a technologů. 2., upr. vyd. Ostrava: ZEROSS, 2001. ISBN 80-85771-85-3.

[9] Technical datasheet LOCTITE® EA 3479 